children" of the hip fracture family. Once a good reduction has been achieved the method of fixation has got to bestow the fracture with good fixation that will not only stand the test of time until union takes place but, equally important, stand the test of the surgeon. If a system of internal fixation is to be seen to work well its results must be reproducible when performed by surgeons throughout the spectrum of grades and orthopaedic experience, from registrars to consultants.

Recently I and some of my colleagues have been using the $\mathrm{AO}$ cancellous screws to achieve an excellent fixation of subcapital fractures in a group of patients whose ages varied from 10 years up to 78 years. We are using a total of two cancellous screws of $16 \mathrm{~mm}$ thread length to ensure that the whole of the thread crosses the fracture and thus gives a very firm compression-fixation of these fractures. This technique is very straightforward, requiring a minimum of dissection and exposure, once a good reduction of the fracture has been obtained. It would seem to be eminently suitable for all grades of surgeon, requiring no complex jigs or other special equipment other than a single guide wire. I should be very interested to know if there are any other groups of orthopaedic surgeons with experience of using similar types of thin screws.

Nuffield Orthopaedic Centre

Headington, Oxford

JoHN DiNLeY

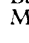

\section{Cimetidine and surgery}

SIR,-It would seem reasonable to assume that the availability of histamine $\mathrm{H}_{2}$ antagonists will significantly alter the attitude of clinicians in their selection of patients for elective surgery in the management of chronic duodenal ulcer. In so far as it is possible to see into the future at present, the indications are that surgery is most likely to be recommended for the young and otherwise healthy dyspeptics who do not respond to adequate therapy over a reasonable time. The choice of operation to be carried out in this younger age group merits careful consideration. It must be safe and it should cause minimal upset to the physiology of the upper gastrointestinal tract.

Whatever form of vagotomy is advocated, the continence of the stomach should be retained wherever possible. The attractive feature of highly selective vagotomy is the absence of any drainage procedure. Some years ago Burge, recognising the disadvantages of accepted drainage procedures, recommended the use of selective vagotomy without drainage in the absence of organic narrowing at the gastric outlet and latterly he too thought that highly selective vagotomy without drainage might well be preferable. However, serious complications of this technically exacting procedure have been recorded ${ }^{2}$ and in any case the recurrent ulcer rate is still a matter for discussion.

Over the past four years we have carried out 65 operations for chronic duodenal ulceration in which truncal vagotomy has been combined with stretching of the pylorus with a Tubbs dilator inserted through a stab gastrotomy. The instrument is opened to the maximum of $4.3 \mathrm{~cm}$ with the object of temporarily inhibiting pyloric function while the vagotomised stomach regains its tone and motility. To date the results are encouraging. No patient has required formal drainage because of gastric stasis. In two instances conversion to gastrojejunostomy has been necessary because of a mechanical hold-up at the gastric outlet. In one of these patients the pylorus had been "cracked" at the time of operation and the defect oversewn "in axis." We accept that the procedure cannot be used in the presence of fibrosis of the pyloric canal, and with the experience now available this patient would not have been included in the series. The other patient developed a penetrating posterior duodenal ulcer and at the conversion procedure an intact posterior vagal trunk was found.

We appreciate that the number of cases in the series is not large and the follow-up period is short, but we feel it justifiable at this juncture to report briefly on an alternative approach to the surgical management of selected cases of chronic duodenal ulcer. This simple operation obviates the sometimes distressing sequelae which occasionally accompany more formal drainage procedures and at the same time retains the physiological "gate-keeping" function of the pyloric canal.

J D THOMSON J B W Galloway 1 Burge, H, British Medical fournal, 1971, 1, 172.
2 Moore, F P, et al, British Medical .7ournal, 1975, 4,
328.
${ }^{3}$ Hopton, D S, et al, British Medical fournal, 1976, 1.
149.

administrative staff in the National Health Service I feel compelled to set out the facts, of which so many critics are unaware.

The Department of Health and Social Security's definition of an administrator can be summed up as "a person who spends part of his working time in an office and who does not deal directly with patients." This definition includes many who spend only a small proportion of their time on office work, the majority being devoted to supervising or assisting those who are caring directly for the patient.

Statistics have been manipulated to try to demonstrate that there are too many administrative staff, the latest demonstrating that there has been a larger increase in administrators than nurses and that the ratio of administrators to hospital beds has increased. These comparisons are carefully selected, quoted out of context, and largely irrelevant. This is not to say that all the administrative work which is done in the NHS is worth while or economic. Members of Parliament and leaders of the medical and other professions may criticise the administrative processes and those who have to operate them, but they were mainly responsible for setting them up.

We went through an exhausting and disturbing experience in 1974 and the NHS has survived only because of the hard work andyes-devotion of the administrative staff. Many were made redundant, many had to retire early, and many of those who kept their jobs have died or suffered serious ill-health from the excessive and quite unnecessary strain imposed by Parliament, the Civil Service, and all other parties to the reorganisation of the NHS in 1974-including the medical profession.

These are simple facts which everyone should know and on behalf of the 720 members of my branch of Nalgo I would like to warn anyone who wishes to impose a second reorganisation on us that we will strenuously resist it. Since the doctors, who probably form the bulk of our critics, no longer consider strike action unethical our choice of methods of resistance is wide.

practitioners up and down the country known this for years. In almshouses, garrets, and council flats you will find, usually written on the back of an envelope and propped on the mantelpiece, the day's dose of drugs carefully spelt out and interpreted.

But you will never see long words like frusemide. Everybody in the outback knows frusemide as Lasix. Not long ago a patient fresh from hospital smacked on my surgery desk three containers bearing the imposing labels, potassium clorazepate, doxepin hydrochloride, and maprotiline hydrochloride. Imagine my relief when I discovered he was only having our old friends Tranxene, Sinequan, and Ludiomil.

In pharmacies, surgeries, and people's houses everywhere trade names are the order of the day. By all means use ego-boosting proper names in hospital if you must, but don't forget to provide a translation when the patient goes home. This improves compliance all round.

Stratford-on-Avon, Warwicks

HaMish Nicol.

\section{Administrative staff in the NHS}

SIR,-In the face of considerable ill-informed criticism from journalists, doctors, and many other quarters about the role and number of

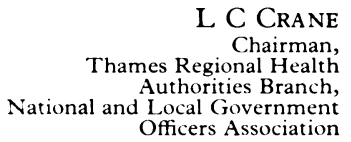

London W2

\section{Loss of doctor in the course of duty}

SIR,-One wonders how deeply Dr G C C MacVicker (19 February, p 512) has inquired into the "victimisation" of the secretary of a community health council "doing the duty laid upon him .... as 'patient's friend.' Possibly he hopes to persuade his local medical committee colleagues to press for a revision of the regulations which allow the general practitioner some choice of patients. Perhaps he feels that his chairmanship of a CHC qualifies him to judge those doctors who exercise that choice. The facts given in a television programme might well be true, but justice demands not only the truth but the whole truth.

Four months ago this secretary submitted a report to his council alleging a "pattern of complaints" against local general practitioners. As an example he cited the details of a formal complaint made by a widow to the Family Practitioner Committee concerning a doctor's treatment of her husband. It was reported that 